\title{
Pacioli 2000: A Systems Review
}

\author{
Dr. Ronald C. Clute, Accounting, Metropolitan State College of Denver \\ Dr. George B. Garman, Computers and Management Information Systems, Metropolitan State College of Denver
}

\begin{abstract}
Pacioli 2000 is a recent entry into the Accounting Information System market. Designed with the small business in mind, Pacioli 2000 is flexible, complete, and fairly easy to use. Pacioli 2000 costs less than \$50.00, yet it has features often only found in Accounting Information Systems costing as much as $\$ 1,000$.
\end{abstract}

\begin{abstract}
About Pacioli 2000
Pacioli $2000^{1}$ is an exceptional accounting program considering the $\$ 49.95$ suggested list price. Office supply warehouses routinely carry Pacioli 2000 for less than $\$ 30.00$. The pricing strategy is to inundate the market with its un-realistically low price. Normally such an accounting program would cost $\$ 250.00$ or more. The list of features is extensive, with abilities that many $\$ 500.00$ packages cannot match, although some aspects of Pacioli 2000 are needlessly complex as our review shows. The remainder of this section contains an overview of the basic features of Pacioli.
\end{abstract}

The general ledger module contains no limit on number of accounts or transactions. The 36 open periods option is one of the most flexible available in accounting programs at any price. Both cash and accrual based systems are allowed. The accounts receivable module offers unlimited numbers of accounts with either open invoice or balance forward. Monthly finance charges, discounts, and terms are also available on receivables.

Pacioli prints monthly statements, user definable aging reports, and mailing labels. The accounts payable module has the same features as accounts receivable. The inventory module allows FIFO, LIFO, average cost, and specific identification methods. Product codes can be 13 characters long - enough to accommodate bar codes. Units of purchase and units of sale need not be the same. Pacioli prints labels, count sheets, inventory reports, price lists, and low inventory product alert reports.

The purchasing module handles purchase orders, purchase returns, and merchandise receiving. Purchases are allowed for inventory, assets, and expensed items. The billing module prepares invoices for services or products along with sales returns and credit memos. Three different invoice formats are supported. The budgeting module provides period to date and year to date data for any one or combination of three years. The auditing module does check reconciliations and reports on audited and unaudited balances. The Pacioli audit trail features are excellent.

Other features includes support for 999 companies with automatic file duplication. Pacioli comes network ready with no limit on users or user fee. Multiple level passwords and file locking are also included. Data can be exported to word processor, database, and spreadsheet programs. Minimum hardware requirements are IBM or compatible, hard disk with 5 MB's free, and 640 $\mathrm{KB}$ of RAM. A color monitor and mouse are recommended. Pacioli comes with both $3 \quad 1 / 2$ and $51 / 4$ diskettes.

\section{Open Periods}

Pacioli allows up to 36 open periods, which exceeds the generally accepted minimum of 13 open periods. This represents a major improvement over many accounting programs costing hundreds of dollars which allow for only one or four open periods.

\section{Support}

Help is on line and context sensitive but does not contain the level of detail one might deem necessary. Error messages are unacceptable. They are not self explanatory nor are they explained adequately in the manual. Your only option to call their no time limit, free support line for assistance. We found the telephone and fax support to be outstanding. There is a 2 $1 / 2$ hour complete video tutor that is very helpful, 
especially for those who are new to automated accounting systems.

\section{The Manual}

The manual was obviously written by someone other than the person who wrote the program. There is much more to Pacioli than the manual indicates. Excellent telephone support, however, somewhat ameliorates the shortcomings of the manual.

\section{Chart of Accounts}

Pacioli comes with a single chart of accounts with hundreds of accounts already set up. The alternative used by many accounting programs is to have charts of accounts already set up for several types of businesses. With Pacioli, one must delete all of the unwanted accounts before entering any data. This is a simple procedure so long as the deleted or changed accounts do not show up on the pre-defined financial statements. Pacioli's financial statements contain the accounts that were in the original chart of accounts and are not altered when the user changes the chart of accounts. For example, if you change the capital accounts in the chart of accounts to reflect sole proprietorship accounts, Pacioli will still print capital accounts for a corporation. The user must use the report generator to change the pre-defined financial statements. This is awkward, but is typical of accounting programs. Accounting programs without a report generator do not allow financial statements to be modified. More expensive accounting programs automatically adjust financial statements to reflect changes in the chart of accounts.

The account numbering scheme is simple to use and more than adequate for even medium sized businesses. Account numbers can have up to ten alphanumeric digits.

\section{Standard Management Reports}

Pacioli offer 25 flexible management reports, excluding financial statements. The aging report, for example, can be sorted by account number, zip code, cycle, and user defined customer codes. A second level sort is allowed for name, credit balance, and account number. Space does not allow for a discussion of every report.

\section{Sales Tax Tables}

Businesses of most types and sizes have difficulty dealing with sales taxes. A typical situation is a furniture store where sales taxes must be collected, allocated, and accounted for according to where the customer lives. The accounting program must compute sales taxes on all sales, receivables, and payables and record the tax in proper accounts. Pacioli allows for up to 999 different tax authority combinations with the tax liability recorded in different accounts. Even the smallest of businesses must allow for taxable and non-taxable sales. Many computerized accounting programs do not calculate sales taxes because of the complexity involved.

\section{Discount Tables}

Pacioli allows for unlimited fixed discounts and volume discounts for both receivables and payables. Up to five levels are permitted for Volume discounts. Both types of discounts can be specified in individual $A / R$, $\mathrm{A} / \mathrm{P}$, and inventory accounts. The discount is automatically computed and recorded in the appropriate account when payment is made.

\section{Terms Tables}

Pacioli allows for unlimited payment terms. All common business terms are already set up in Pacioli. Terms discounts can be specified in individual $A / R$ and $\mathrm{A} / \mathrm{P}$ accounts. The terms discount is automatically computed and recorded in the appropriate account when payment is made.

\section{Inventories}

Inventories may be categorized by product line. Purchase and sales information need not have the same base. In other words, purchases may be by the case and sales by the unit. Pacioli automatically converts one to the other. Revenue accounts and COGS accounts can be specified for each inventory item. It is a simple matter to maintain this information by product line, salesperson, et cetera. Additional purchase information includes cost per unit, supplier we buy from, discount granted us (our terms would be specified in the A/P), location of inventory, and negative allowed?. Additional sales information includes standard sales price, three types of discounts we grant, and whether sales taxes should be computed.

Additional inventory information provided includes average cost, last purchase cost, cost according to the costing method chosen, numbers of units and total cost of units on hand, number of units received but not posted, number of units sold but not posted, number of units available for sale, number of units on order from supplier, desired minimum stock, and number of units to re-order. Three years of historical data are provided for purchases units and dollars and sales units and dollars. 


\section{$\mathbf{A} / \mathbf{R}$ and $\mathbf{A} / \mathbf{P}$}

The $\mathrm{A} / \mathrm{R}$ and $\mathrm{A} / \mathrm{P}$ features are truly exceptional. Fields available for these accounts include: account number, account name, contact person, two line address, city, state, nine digit zip, telephone number, fax number, memo field printed on checks, tax ID number, VIA and FOB, code 1 (user defined), code 2 (user defined), terms $(2 / 10 /$ net 30 , etc.), price code (four different base prices are allowed on each inventory item), tax table number (see above), credit limit, account balance, credit available, and balance type (balance forward and open invoice). Pacioli's $A / R$ and $A / P$ features are as extensive and as flexible as accounting programs costing several thousands of dollars. A minor inconvenience is Pacioli's requirement of a separate chart of accounts account number for each receivable and payable. By contrast, inventory items do not require a separate chart of accounts account number.

\section{Financial Statements}

Pacioli comes with six pre-defined financial statements. There are three variations each of balance sheets and income statements. Notably absent is a statement of cash flows. However, most accounting programs under $\$ 500.00$ do not offer this statement. Pacioli does have a report generator, which is really unique even in much more expensive accounting programs. The user can modify any of the pre-defined financial statements or generate an entirely new statement. The report generator is somewhat awkward but very usable.

\section{Factory Accounting Not Supported}

Pacioli does not offer job costing with the type of detail found in accounting programs of similar quality. Peachtree III, for example, offers a comprehensive job costing module. Of course, Peachtree costs around $\$ 300.00$, too. As a result, Pacioli is not appropriate for manufacturing companies. Pacioli would be a wise choice for small to mid-size retail and wholesale companies. Service companies of any size could use Pacioli.

\section{Audit Trail and Security}

Since Pacioli allows a maximum of 999 companies, a highly developed security system is in place to protect the data of individual companies and to provide extensive audit trails. Nine levels of security are allowed for any company. Since Pacioli is designed to be used on a network, an administrative password should exist that would allow the administrator to perform any function on any company.

\section{Suggestions for Improvement}

Although Pacioli 2000 is an excellent product for its price, we feel there are some areas that need improvement. First, a much better user's manual is needed. Second, some terminology within the program is confusing. For example, "Standard Cost" does not mean standard cost in the way accountants generally use the term. Third, menu options are sometimes unclear. For example, the set-up option for "create a new company" does not really create a new company. Fourth, when Pacioli is started, the last company used is automatically loaded. This can create confusion if a CPA firm has several clients. We suggest a menu listing the available companies be offered before the main menu appears. Finally, Pacioli's chart of accounts is designed for corporate structures. We suggest a separate chart of account for proprietorships, partnerships, and corporations which would be selected when the company is first created.

\section{Screen Layout}

Pacioli's quest for a minimum number of display screens one must learn sometimes leads to confusion. For example, a sales invoice and purchase order use a common screen. Making the purchase order screen look like a manual purchase order and the sales invoice screen look like a manual sales invoice would be less confusing. You are confronted with purchase order type fields when completing a sales invoice, and vis versa. There are simply too many fields that are not common to both forms. This confusion does not occur with $A / R$ and $\mathrm{A} / \mathrm{P}$ screens which are the same because their manual counterparts are almost identical.

\section{Conclusion}

Pacioli is generally an outstanding accounting program that should be priced at $\$ 249.95$, rather than $\$ 49.95$. However, there are some traps in the program that will presumably be corrected in future versions. The biggest trap is that the chart of accounts must be adjusted to your circumstances before any data is entered. This is a fairly standard requirement in many accounting programs. However, in Pacioli the rule is not explicitly stated. The problem is that once an account is used, it must remain dormant for three years before the account can be deleted. This makes sense from an audit trail standpoint, but it can be frustrating when you are setting up Pacioli for the first time. Another trap is that Pacioli automatically places the user into the company used last. The first screen should have been a scrollable screen of companies. 


\section{Suggestions For Future Research}

Academic researchers need to be more involved in computerized accounting problems. We in academic accounting research generally concentrate on manual accounting research problems because we only teach manual accounting. Unfortunately, many of the problems found in computerized accounting are quite different from the problems found in manual accounting. The entire business world of accounting has been computerized for years. Academic research can be made more relevant to the business world by greater involvement in problems found in computerized accounting.

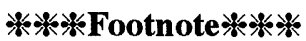

1. Pacioli 2000 has won numerous awards for being a best buy computerized accounting package.

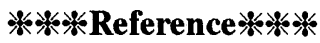

1. Pacioli 2000 is produced and distributed by MUSA Business Systems, Inc. 17440 North Dallas Parkway, Suite 207, Dallas Texas 75287. 